\title{
Pengelolaan Sampah Dengan Metode 3r Berbasis Gampong (Pilot Project: Gampong Serambi Indah, Kecamatan Langsa Barat, Kota Langsa)
}

\author{
Yeggi Darnas ${ }^{1,4}$, Maula Audiana ${ }^{1}$, Muhammad Nizar ${ }^{2}$, Riska Yolanda $^{3}$, Elita Amrina ${ }^{4}$ \\ ${ }^{1}$ Prodi Teknik Lingkungan, Fakultas Sains dan Teknologi UIN Ar-Raniry, \\ ${ }^{2}$ Prodi Teknik Lingkungan Fakultas Teknik, Universitas Serambi Mekkah \\ ${ }^{3}$ Balai Besar Pelatihan dan Pemberdayaan Masyarakat Desa, Daerah Tertinggal \& Transmigrasi, Kementerian Desa, PDT \\ \&Transmigrasi RI \\ ${ }^{4}$ Program Studi Program Profesi Insinyur Program Pascasarjana Universitas Andalas \\ Correspondence email: darnasjunior@ar-raniry.ac.id
}

\begin{abstract}
Abstrak. Upaya untuk mengatasi penangan sampah di sumber, terutama pada daerah pedesaan harus melibatkan pemangku kepentingan dan masyarakat desa itu sendiri. Gampong Serambi Indah, Kecamatan Langsa Barat terletak di pinggir provinsi Aceh, potensial untuk mengelola sampah di desa sesuai dengan ketentuan yang berlaku dan diharapkan nantinya dapat meningkatkan perekonomian masyarakat desa dengan pengelola sampah. Tujuan penelitian ini adalah merencanakan sistem pengelolaan sampah berbasis gampong dengan mendirikan Bank Sampah untuk income bagi Gampong. Metode penelitian berupa survey partisipasi masyarakat terhadap pengelolaan sampah dan penghitungan sampling sampah mengacu pada SNI 19-3964 1994. Hasil penelitian menunjukkan bahwa timbulan sampah gampong Serambi Indah yang adalah $0,14 \mathrm{~kg} / \mathrm{orang} / \mathrm{hari}$ atau 1,16 L/orang/hari dengan komposisi terdiri dari $20 \%$ plastik, $1 \%$ kaca, 53\% sisa makanan (organik), 5\% kain/tekstil, $2 \%$ kertas dan 19\% kayu. Tingkat pelayanan pengelolaan sampah di gampong ini baru 54\%. Dengan adanya Bank sampah ini diharapkan dapat mengurangi sampah sebesar 59\% yaitu sebesar $181 \mathrm{~kg}$ dari $370 \mathrm{~kg}$ yang diangkut ke TPA.
\end{abstract}

Kata kunci: bank sampah, Gampong Serambi Indah, komposisi sampah, partisipasi, masyarakat, pengelolaan sampah

\section{PENDAHULUAN}

Menurut Damanhuri dan Padmi (2016), pengendalian pencemaran dari sampah yang disebabkan oleh aktivitas manusia dan alam adalah tujuan dasar dari pengelolaan sampah. Sistem pengelolaan sampah yang terdapat di Indonesia pada umumnya masih menggunakan tata cara lama yaitu dengan cara kumpul-angkut-buang. Pilihan setiap kota untuk menyelesaikan permasalahan tersebut yaitu dengan pengurukan di Tempat Pemrosesan Akhir (TPA) sehingga muncul berbagai kasus kegagalan TPA akibat kesalahan dalam pengoperasiannya. Salah satunya yaitu tidak dilakukan proses penanganan dan pengurangan sampah di sumber. Apabila tidak ditangani dengan benar maka dapat menimbulkan berbagai dampak terhadap manusia, hewan dan lingkungan. Seperti estetika, vektor penyakit, bau dan debu, pencemaran air, bahaya kebakaran dan menyumbat saluran air. Rohani (2007) menyebutkan, masyarakat Desa Medan Senembah Kecamatan Tanjung Morawa melakukan penanganan sampah mereka dengan cara membakar dan membuang ke lahan kosong, sehingga ketika musim hujan tiba dapat menyebabkan banjir karna tergenangnya air yang tersumbat oleh sampah di drainase.

Berdasarkan observasi tanggal 6 Maret 2019 terhadap sistem pengelolaan sampah pada Gampong Serambi Indah, sistem pewadahan di sumber pada Gampong ini menerapkan pewadahan individual berupa keranjang sampah dan kantong plastik/tong sampah dengan menempatkannya di halaman rumah masing-masing tanpa dilakukan pemilahan. Sistem pengumpulan sampah di gampong ini, menerapkan pola pengumpulan individual tidak langsung menggunakan becak motor yang disediakan DLH Kota Langsa, pengumpulan dilakukan pertiga hari sekali. Selanjutnya sistem pemindahan dari becak motor ke container yang berada di area Pool Truck yang terletak di halaman Kantor DLH, kemudian diangkut ke TPA. Pada lokasi TPA dilakukan pemilahan sampah yang masih bernilai ekonomi dan residua tau sampah yang tidakbernilai ekonomis diurug serta ditimbun di lahan urug dan dipadatkan menggunakan bulldozer.

Berdasarkan Qanun Kota Langsa Nomor 3 Tahun 2014 tentang Pengelolaan Sampah, pengelolaan sampah rumah tangga dan sampah sejenis rumah tangga, dimana setiap orang diharuskan melakukan penanganan dan pengurangan sampah yang berbasis lingkungan. Masyarakat diharuskan mengurangi timbulan sampah dari sumbernya dengan pendekatan pengurangan (reduce), penggunaan ulang (reuse), pendauran ulang (recycle) yang disingkat dengan 3R serta memilah sampah. Untuk mempermudah pengendalian sampah, diwajibkan menyediakan tempat penampungan sampah di pekarangan, yang berfungsi sebagai tempat pewadahan sampah sehari-hari.

Peran serta masyarakat gampong dalam pengelolaan sampah sangat dibutuhkan, baik sebagai pengelola, pengolah, pemanfaat, serta penyedia dana untuk mengelola sampah dan pengawas kegiatan pengelolaan sampah. Dan pemerintah sebagai pengelola berhak menerapkan sistem pengelolaan sampah yang sesuai dengan kebutuhan masyarakat. 
Tingkat pelayanan pengelolaan sampah yang terlayani DLH pada Gampong Serambi Indah saat ini baru 54\% daerah terlayani. Padahal dalam penerapan pengelolaan sampah sangat dibutuhkan dukungan pemerintah dan peran serta masyarakat, baik dari aspek teknis (pengurangan, pemilahan dan penanganan) maupun non teknis (struktur kelembagaan, pembiayaan dan partisipasi masyarakat agar ikut serta dalam kegiatan penanganannya). Sesuai dengan rencana strategi Gampong Serambi Indah pada tahun 2021 untuk mengadakan program bank sampah gampong, maka dimulailah dengan mewajibkan masyarakat menangani sampah dengan cara memilah sampahnya sendiri, kemudian mengantarkan ke bank sampah atau Tempat Pengelolaan Sampah reduce, reuse dan recycle (3R) dan disini direncanakan dibangun Bank Sampah sehingga sampah yang diangkut ke TPA dapat berkurang. Sampah yang diangkut ke TPA hanya residu sehingga umur TPA dapat bertambah. Dan menjadikan masyarakat lebih mandiri dalam mengelola sampahnya.

\section{Rumusan Masalah}

Adapun rumusan masalah pada penelitian ini adalah:

1. Bagaimanakah prilaku masyarakat dalam pengelolaan sampah di Gampong Serambi Indah?

2. Bagaimana perencanaan pengelolaan sampah di Gampong Serambi Indah dengan melibatkan partisipasi masyarakat?

\section{Tujuan Penelitian}

Adapun tujuan pada penelitian ini adalah:

1 Mengetahui prilaku masyarakat dalam pengelolaan sampah di Gampong Serambi Indah saat ini.

2 Merencanakan pengelolaan sampah dengan melibatkan partisipasi masyarakat di Gampong Serambi Indah.

\section{METODE}

Penelitian ini menggunakan metode kualitatif dan kuantitatif. Data yang dibutuhkan berupa data primer dan data sekunder. Data sekunder yang dibutuhkan adalah:

1. Peta administrasi gampong didapat dari kantor keuchik Gampong Serambi Indah.

2. Data jumlah penduduk Gampong Serambi Indah didapat dari kantor keuchik Gampong Serambi Indah.

3. Kondisi pengelolaan sampah seperti pengumpulan dan timbulan sampah yang diangkut ke TPA dari Gampong Serambi Indah didapat dari DLH Kota Langsa.

Data primer yang dibutuhkan berdasarkan SNI 19-3964-1994 adalah sebagai berikut:

1. Timbulan dan komposisi sampah didapat dari hasil sampling sampah

2. Data hasil wawancara didapat dari wawancara langsung dan kuesioner kepada masyarakat.

\section{Pengolahan dan Analisis Data}

1 Perhitungan penduduk 10 tahun yang akan datang atau pada tahun 2029 menggunakan Metode Aritmatika.

2 Analisis timbulan dan komposisi sampah.

3 Perhitungan sampling sampah mengacu pada SNI 19-3964 1994.

Pengukuran dan perhitungan contoh timbulan sampah harus mengikuti ketentuan SNI 19-3963 1994 sebagai berikut:

a. Satuan yang digunakan dalam pengukuran timbulan sampah adalah:

1) Volume basah (asal) : liter/unit/hari;

2) Berat basah (asal) : kilogram/unit/hari;

b. Satuan yang digunakan dalam pengukuran komposisi sampah adalah dalam \% berat basah/asal.

c. Jumlah unit masing-masing lokasi pengambilan contoh timbulan sampah, yaitu:

1) Perumahan : jumlah jiwa dalam keluarga;

2) Sekolah : jumlah murid dan guru;

3) Kantor : jumlah pegawai;

d. Metode pengukuran contoh timbulan sampah, yaitu:

1) Sampah terkumpul diukur volume dengan wadah pengukur 40 liter dan ditimbang beratnya; dan/atau;

2) Sampah terkumpul diukur dalam bak 500 liter dan ditimbang beratnya kemudian dipisahkan komponen sampah dan ditimbang beratnya.

4 Perhitungan bobot nilai survey menggunakan Skala Likert.

5 Analisis perencanaan pengelolaan sampah mengacu pada Qanun Kota Langsa Nomor 3 Tahun 2014 tentang Pengelolaan Sampah 
Yeggi Darnas et al., Pengelolaan Sampah Dengan Metode 3r Berbasis Gampong (Pilot Project: Gampong Serambi Indah, Kecamatan Langsa Barat, Kota Langsa)

\section{HASIL DAN PEMBAHASAN}

Timbulan dan Komposisi Sampah Domestik

Penentuan jumlah penduduk Gampong Serambi hingga tahun 2029, diproyeksikan berdasarkan data jumlah penduduk 2014 - 2019 dari kantor keuchik. Data jumlah penduduk Gampong Serambi tahun 2014 - 2019, serta proyeksi penduduk Gampong Serambi Indah dari 2020 sampai 2029 dapat dilihat pada tabel 1.

Tabel 1. Proyeksi Penduduk Gampong Serambi Indah 2020 - 2029

\begin{tabular}{ccccc}
\hline No & Tahun & Jumlah Penduduk & Timbulan Sampah L/Orang/Tahun & Timbulan Sampah L/tahun \\
\hline 1 & 2014 & 1.190 & $1.380,40$ & 1.642 .676 \\
2 & 2015 & 1.209 & $1.402,44$ & 1.695 .550 \\
3 & 2016 & 1.216 & $1.410,56$ & 1.715 .241 \\
4 & 2017 & 1.201 & $1.393,16$ & 1.673 .185 \\
5 & 2018 & 1.120 & $1.299,20$ & 1.455 .104 \\
6 & 2019 & 1.203 & $1.395,48$ & 1.678 .762 \\
7 & 2020 & 1.203 & $1.395,98$ & 1.679 .972 \\
8 & 2021 & 1.204 & $1.396,49$ & 1.681 .182 \\
9 & 2022 & 1.204 & $1.396,99$ & 1.682 .393 \\
10 & 2023 & 1.205 & $1.397,49$ & 1.683 .604 \\
11 & 2024 & 1.205 & $1.397,99$ & 1.684 .815 \\
12 & 2025 & 1.206 & $1.398,50$ & 1.686 .027 \\
13 & 2026 & 1.206 & $1.399,00$ & 1.687 .239 \\
14 & 2027 & 1.206 & $1.399,50$ & 1.688 .452 \\
15 & 2028 & 1.207 & $1.400,00$ & 1.689 .665 \\
16 & 2029 & 1.207 & $1.400,51$ & 1.690 .878 \\
\hline
\end{tabular}

Sebelum melakukan sampling, maka dihitung terlebih dahulu jumlah jiwa yang akan disampling berdasarkan SNI 19-3964-1994 sebagai berikut:

$\mathrm{S}=\mathrm{Cd} \sqrt{\mathrm{Ps}}(1)$

Dimana :

S = Jumlah Sampling

$\mathrm{Cd} \quad=$ koefisien perumahan, dimana untuk Kota Langsa adalah kota sedang $=0,5$

Maka :

$\mathrm{S} \quad=0,5 \sqrt{1.207}$

$=17,37$

$\approx 18$ jiwa

Jadi, total jiwa yang disampling adalah sebanyak 18 jiwa. Perhitungan rumah (KK) yang akan disampling adalah sebagai berikut:

$\mathrm{KK}=\frac{S}{\mathrm{n}}$

Dimana $\mathrm{n}$ adalah jumlah jiwa per $\mathrm{KK}=5 \mathrm{jiwa} / \mathrm{rumah}$

$$
\begin{aligned}
\mathrm{KK} & =\frac{18}{5} \\
& =3,5 \\
& \approx 4 \text { rumah }
\end{aligned}
$$

Hasil perhitungan rumah yang disampling adalah 4 rumah. Terbagi dengan tiga kategori, yaitu: High Income, Medium Income dan Low Income. Jika hanya empat rumah yang disampling, maka data yang didapat tidak seimbang, karena kategori rumah yang disampling sebanyak tiga kategori, maka satu rumah yang disampling antara tiga kategori tidak diketahui akan disampling pada kategori yang mana. Untuk melengkapi data agar seimbang, maka rumah yang disampling adalah sebanyak enam rumah, masing-masing kategori mendapat dua rumah untuk dilakukan sampling. Rumah yang disampling didapat dari arahan keuchik berdasarkan data yang terdapat di kantor keuchik.

Berdasarkan sampling sampah yang dilakukan, didapat timbulan sampah sebanyak 1,16 L/orang/hari. Rata-rata komposisi sampah yang terdapat di timbulan tersebut terdiri dari sisa makanan (organik) sebanyak 3,31 kg/hari, kayu $1,84 \mathrm{~kg} /$ hari, plastik sebanyak 0,65 kg/hari, kertas sebanyak $0,7 \mathrm{~kg} / \mathrm{hari}$, kaca sebanyak $0,16 \mathrm{~kg} / \mathrm{hari}$, kain/tekstil 0,08 $\mathrm{kg} / \mathrm{hari}$ dan Karet/kulit sebanyak $0,03 \mathrm{~kg} / \mathrm{hari}$. Komposisi sampah yang terbanyak yaitu komponen sisa makanan (organik) disebabkan oleh pola konsumsi masyarakat yang dilakukan. 
Yeggi Darnas et al., Pengelolaan Sampah Dengan Metode 3r Berbasis Gampong (Pilot Project: Gampong Serambi Indah, Kecamatan Langsa Barat, Kota Langsa)

\section{Timbulan Sampah Non Domestik}

Timbulan sampah untuk non domestik sumbernya ada 2, yaitu kantor keuchik Gampong Langsa dan Sekolah Dasar (SD) Negeri Seuriget yang terletak di Jalan T. Muda Dusun Cut Mutia Gampong Serambi Indah, Birem Puntong, Langsa. Hasil timbulan sampah juga didapat dari sampling selama 8 hari berturut-turut sesuai dengan SNI 19-3964 1994. Timbulan sampah SDN dihitung berdasarkan rumus berikut :

$\mathrm{S}=\mathrm{Cd} \sqrt{\mathrm{Ts}}(2)$

Dimana :

$\mathrm{Cd} \quad=1$

Ts $\quad=$ adalah jumlah kelas $=6$

Sehingga

$\mathrm{S} \quad=1 \sqrt{6}$

$=2,5$

$=3$ Kelas

Maka sampling di SDN Seuriget dilakukan di 3 kelas, lalu didapat timbulan sampah yaitu 0,02 kg/Orang/Hari atau 0,19 L/Orang/Hari. Timbulan sampah kantor keuchik yang didapat setelah melakukan sampling selama 8 hari berturut-turut sesuai dengan SNI 19-3964 1994 yaitu 0,07 kg/Orang/Hari atau 0,603 L/Orang/. Maka rata-rata timbulan sampah penduduk Gampong Serambi Indah adalah 0,14 kg/orang/hari atau 1,16 L/orang/hari.

\section{Partisipasi Masyarakat}

Partisipasi masyarakat didapat melalui hasil wawancara dalam bentuk beberapa pertanyaan. Jumlah sampel untuk rumah (KK) yang akan diwawancara dihitung berdasarkan Roscoe, Gay dan Diehl (dalam Astuti, 2013). Karena penelitian ini bersifat deskriptif maka diambil $10 \%$ dari rumah atau KK. Berdasarkan SNI diasumsikan $1 \mathrm{KK}$ berjumah 5 orang, sehingga jumlah $\mathrm{KK}=242$. Maka didapatkan jumlah sampel:

\section{$=10 \% \times 242$}

$=24,2$ sampel

Sampel sebanyak 24,2 digenapkan menjadi 30 sampel agar tingkat kesalahan data dapat diminimalisir. Hasil wawancara kuisoner partisipasi masyarakat dapat dilihat pada gambar 1. Persentase partisipasi masyarakat dapat dilihat bahwa partisipasi masyarakat Gampong Serambi Indah yaitu sebesar $82 \%$ bernilai sangat buruk, ini dilihat dari kebiasaan masyarakat yang belum melakukan pemilahan sampah.

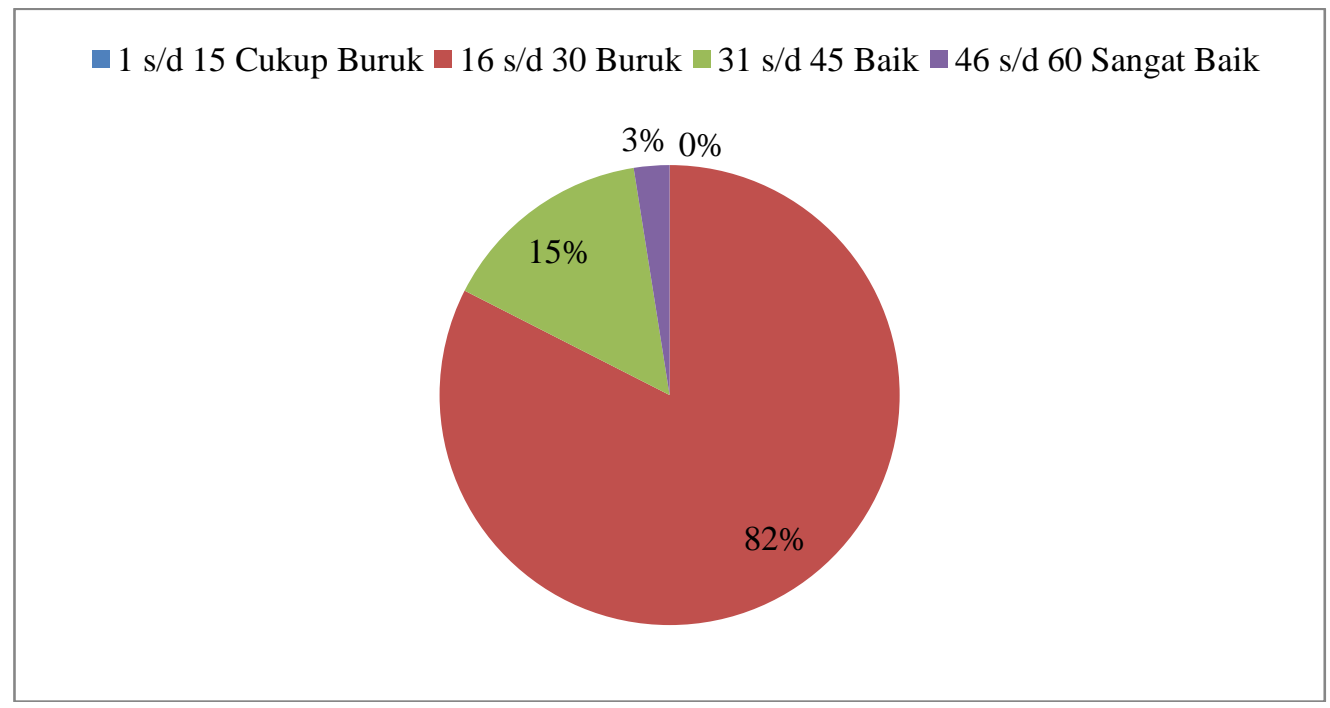

Gambar 1. Partisipasi masyarakat

\section{Perhitungan Skor Kuisioner}

Perhitungan skor/nilai didapat dari kuisioner yang ditanyakan langsung kepada 30 orang/KK di Gampong Serambi Indah. Perhitungan ini bertujuan untuk mengetahui apakah perencanaan pengelolaan sampah dengan melibatkan masyarakat dibutuhkan di gampong ini, didapatkan berdasarkan survey yang dilakukan. Untuk perhitungan hasil digunakan skala likert sebagai suatu metoe pengukuran, dimulai dengan menentukan skala jawaban dengan penentuan nilai. Setelah itu dilakukan penentuan skor kriterium, menentukan nilai rating skala hingga menentukan hasil akhir. Penentuan skala jawaban dapat dilihat pada Tabel 2. 
Yeggi Darnas et al., Pengelolaan Sampah Dengan Metode 3r Berbasis Gampong (Pilot Project: Gampong Serambi Indah, Kecamatan Langsa Barat, Kota Langsa)

Tabel 2. Skala Jawaban

\begin{tabular}{lc}
\hline \multicolumn{1}{c}{ Skala Jawaban } & Nilai \\
\hline Sangat Dibutuhkan (SD) & 4 \\
Dibutuhkan (D) & 3 \\
Cukup Dibutuhkan (CD) & 2 \\
Kurang Dibutuhkan (KD) & 1 \\
\hline
\end{tabular}

Setelah menentukan nilai pada tiap skala jawaban, dihitung skor kriterium berdasarkan nilai skala dan jumlah responden (masyarakat yang diwawancara), yaitu:

Skor kriterium $=$ nilai skala jawaban $\times$ jumlah responden

Dalam penerapan perhitungan kriterium, dilakukan normalisasi nilai kriterium dengan persamaan, berikut:

Skor Kriterium $=\frac{\text { nilai skala jawaban }}{\text { nilai skala jawaban terbesar }} \times 100(3)$

Setelah diperoleh nilai kriterium tiap-tiap skala, kemudian dilanjutkan dengan menentukan nilai skala rating. Untuk nilai skala rating ditentukan nilai batas bawah terendah 1 karena saat pernyataan harus dijawab. Kemudian untuk nilai batas atas dan bawah masing-masing skala dapat diketahui sebagai berikut:

$\begin{array}{ll}\text { Batas atas } & =\text { skor kriterium } \\ \text { Batas bawah KD } & =\text { batas bawah terendah } \\ \text { Batas bawah CD } & =\text { batas atas } \mathrm{KD}+1 \\ \text { Batas bawah D } & \text { = batas atas } \mathrm{CD}+1 \\ \text { Batas bawah SD } & =\text { batas atas } \mathrm{D}+1\end{array}$

Untuk mencari frekuensi masing-masing skala jawaban digunakan rumus:

Hasil $=$ frekuensi kemunculan jawaban $\times$ nilai skala

Setelah diperoleh hasil dari masing-masing skala jawaban, lalu seluruh hasil dijumlahkan dengan rumus di bawah ini:

Skor akhir = hasil SD + hasil D + hasil CD + hasil KD

Tabel 3. Kriterium dan Rating Skala

\begin{tabular}{lcccc}
\multicolumn{1}{c}{ Skala Jawaban } & Jumlah Responden & Nilai Skala & Skor Kriterium & Rating Skala \\
\hline Sangat Dibutuhkan (SD) & 30 & 4 & 100 & $76-100$ \\
Dibutuhkan (D) & 30 & 3 & 75 & $51-75$ \\
Cukup Dibutuhkan (CD) & 30 & 2 & 50 & $26-50$ \\
Kurang Dibutuhkan (KD) & 30 & 1 & 25 & $1-25$ \\
\hline
\end{tabular}

Setelah diketahui kriterium dan rating skala tiap skala jawaban, dihitung tiap skala jawaban berdasarkan jumlah responden. Didapat hasil pengukuran seperti Gambar 4 berikut:

\section{Skor/Nilai Kuisioner}

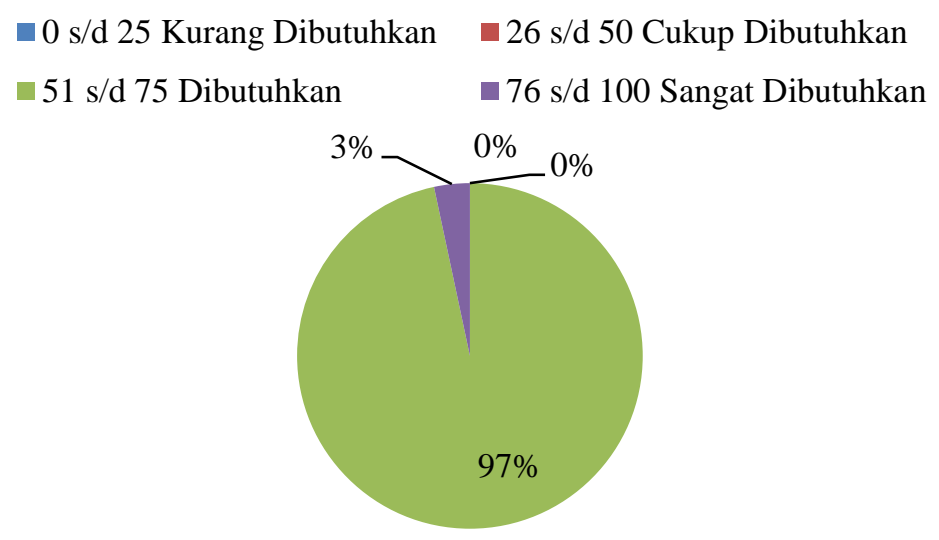

Gambar 2. Skor/nilai kuesioner 
Yeggi Darnas et al., Pengelolaan Sampah Dengan Metode 3r Berbasis Gampong (Pilot Project: Gampong Serambi Indah, Kecamatan Langsa Barat, Kota Langsa)

Berdasarkan hasil perhitungan skor/nilai kuesioner yang didapat dari perhitungan menggunakan skala likert dengan skala jawaban dibutuhkan dengan persentase $97 \%$. Maka, pengelolaan sampah dengan partisipasi masyarakat di Gampong Serambi Indah dapat diterapkan di gampong ini.

\section{Perencanaan Pengelolaan Sampah dengan Metode 3R Berbasis Gampong}

Perencanaan ini diawali dengan sosialisasi kepada masyarakat, sistematika Bank Sampah yang akan dibentuk, penanganan dan pengelolaan sampah yang akan diterapkan di rumah masing-masing dan di gampong.

\section{Aspek Teknis}

1. Daerah layanan dan tingkat layanan

Perencanaan tingkat layanan pengelolaan sampah di Gampong Serambi Indah adalah 100\%, mencakup tiga dusun yaitu Dusun Cut Mutia, Dusun Pocut Baren dan Dusun Cut Nyak Dhien.

2. Sistem Manajemen Pengelolaan Sampah

Sistem Manajemen Pengelolaan Sampah pada Gampong Serambi Indah, dapat dilihat pada Diagram Alir gambar 4. Dimana setelah sampah dikumpulkan dari sumber sampah dibawa ke TPS 3R yang berfungsi sebagai Bank Sampah. TPS 3R ini dibangun pada lahan seluas $453 \mathrm{~m}^{2}$ dapat dilihat pada Gambar 5.

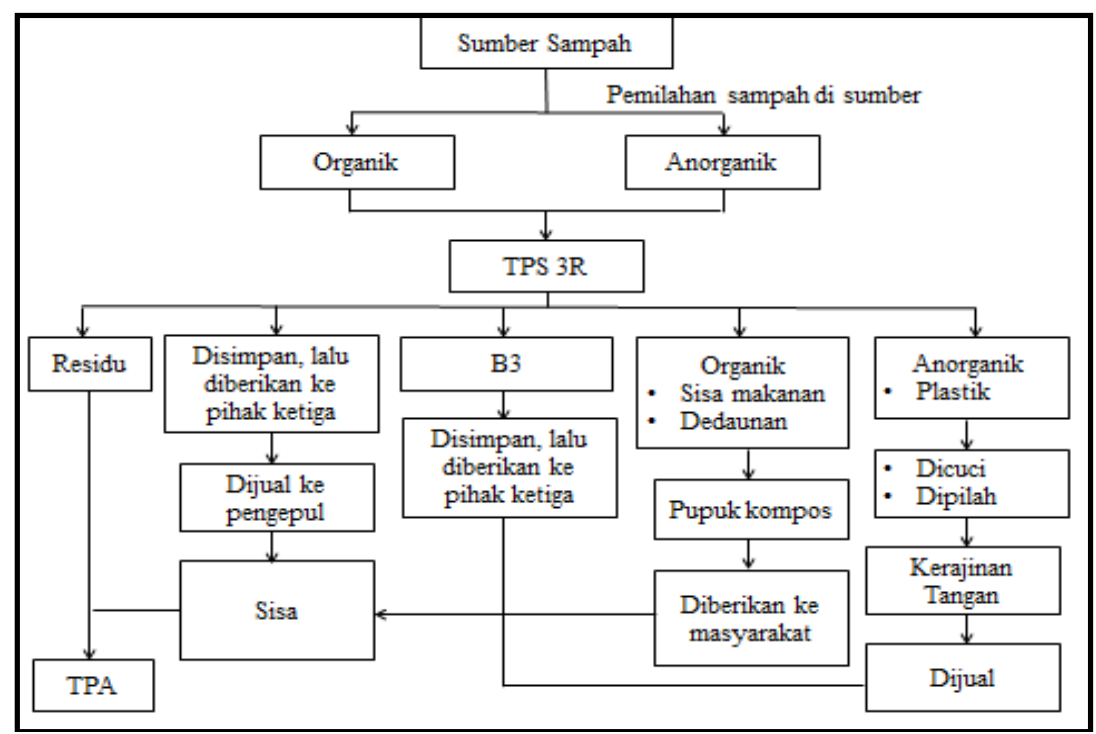

Gambar 3. Sistem Manajemen Penanganan Sampah Gampong

1) Pewadahan di Sumber

Berdasarkan perhitungan timbulan sampah sesuai dengan SNI 19-3964-1994, rata-rata timbulan sampah yang dihasilkan oleh masyarakat Gampong Serambi Indah adalah 0,14 kg/orang/hari atau 1,16 L/orang/hari $=1.207$ orang $\times 1,16 \mathrm{~L} / \mathrm{orang} / \mathrm{hari}$

$=1.400,51 \mathrm{~L} / \mathrm{hr}$

Jadi, timbulan sebanyak 1400,51 L/Hari. Pemilahan dilakukan langsung di sumber, pengumpulan dilakukan sebanyak satu hari sekali. Untuk pewadahan di sumber, dibagi menjadi 2 (dua) yaitu organik dan anorganik. Untuk perhitungan volume pewadahan adalah sebagai berikut:

Pewadahan $=\frac{\text { Timbulan Sampah }}{\text { Jumlah KK }}(3)$

$=\frac{1.400,51 \mathrm{~L}}{242}$

$=5,78 \mathrm{~L}$

Karena pewadahan hanya 2 (dua) yaitu organik dan anorganik, sehingga pewadahan dapat menggunakan bin 3

L. Hal ini disebabkan jumlah sampah organic dengan non organik berbanding $1: 1$.

2) Sistem Pengumpulan

Armada pengumpul di Gampong Serambi Indah menggunakan satu buah becak motor dengan ritasi satu hari sekali. Dengan perhitungan sebagai berikut:

1 becak motor $=1000 \mathrm{~L}$

1 hari 1 kali, mengumpulkan 4,96 L/kk

$=282 \times 4,96$ 
Yeggi Darnas et al., Pengelolaan Sampah Dengan Metode 3r Berbasis Gampong (Pilot Project: Gampong Serambi Indah, Kecamatan Langsa Barat, Kota Langsa)

$$
\begin{aligned}
& =1400,51 \mathrm{~L} / \text { Hari } \\
& =1,4 \mathrm{~m}^{3}
\end{aligned}
$$

Dikarenakan kapasitas becak motor hanya 1000 L, maka becak motor dimodifikasi agar dapat menampung timbulan sampah sebanyak $1,4 \mathrm{~m}^{3}$.

Waktu bongkar muat yang dibutuhkan $=0,16$ jam/ritasi (10 menit)

Kecepatan kendaraan $15 \mathrm{~km} / \mathrm{jam}$

Jarak pengumpulan $2,56 \mathrm{~km}$

Waktu pengumpulan $=2,56 \mathrm{~km}: 15 \mathrm{~km} / \mathrm{jam}$

$=0,17 \mathrm{jam}$

Waktu pengumpulan $=0,16 \mathrm{jam}+0,17 \mathrm{jam}$

$=0,33 \mathrm{jam}$

Waktu kerja pengumpulan pukul 09.00-10.00 WIB

3) Sistem Pengolahan di TPS 3R (Bank Sampah)

Pengolahan sampah dilakukan sesuai dengan komposisi masing-masing sampah, yaitu berdasarkan hasil sampling komposisi sampah.

- Plastik

- Sampah plastik sebanyak $10 \%$, maka dilakukan pencacahan. Sebelumnya sampah plastik ini dicuci terlebih dahulu kemudian dipilah berdasarkan warna atau berdasarkan jenis plastiknya, setelah itu dilakukan pencacah menjadi bijih plastic yang siap dijual ke Industri yang membutuhkan. Dana yang didapat dari hasil penjualanan dikembalikan ke Bank Sampah sebagai dana operasional.

- B3 (bahan berbahaya dan beracun)

Bahan berbahaya dan beracun (B3) tidak dilakukan pengelolahan melainkan hanyadiantar ke TPA untuk diserahkan kepada pihak ketiga yang melakukan penanganan.

- Organik

- Komponen organik berdasarkan sampling ada sebanyak 53\%. Sampah organik ini berupa sampah sisa makanan dan halaman, sampah organik ini akan diproses menjadi pupuk. Proses pembuatan pupuk secara tertutup menggunakan teknologi komposter portable dari drum. Hasil dari pupuk ini berupa pupuk cair, pupuk yang sudah jadi dapat dibagikan ke penduduk sekitar sebagai suatu apresiasi karena sudah berpartisipasi dalam proses pengelolaan sampah di gampong. Dan jika ada masyarakat yang ingin membuat pupuk kompos sendiri di rumah masing-masing, maka akan dilakukan sosialisasi dan pelatihan pebuatan pupuk kepada masyarakat.

\section{Aspek non teknis}

1) Struktur kelembagaan

Struktur kelembagaan yang mengatur sistem pengelolaan sampah di Gampong Serambi Indah dipilih dengan cara musyawarah antara perangkat gampong. Setelah terbentuk, akan diumumkan kepada masyarakat. Struktur kelembagaan terlihat pada Gambar 4.

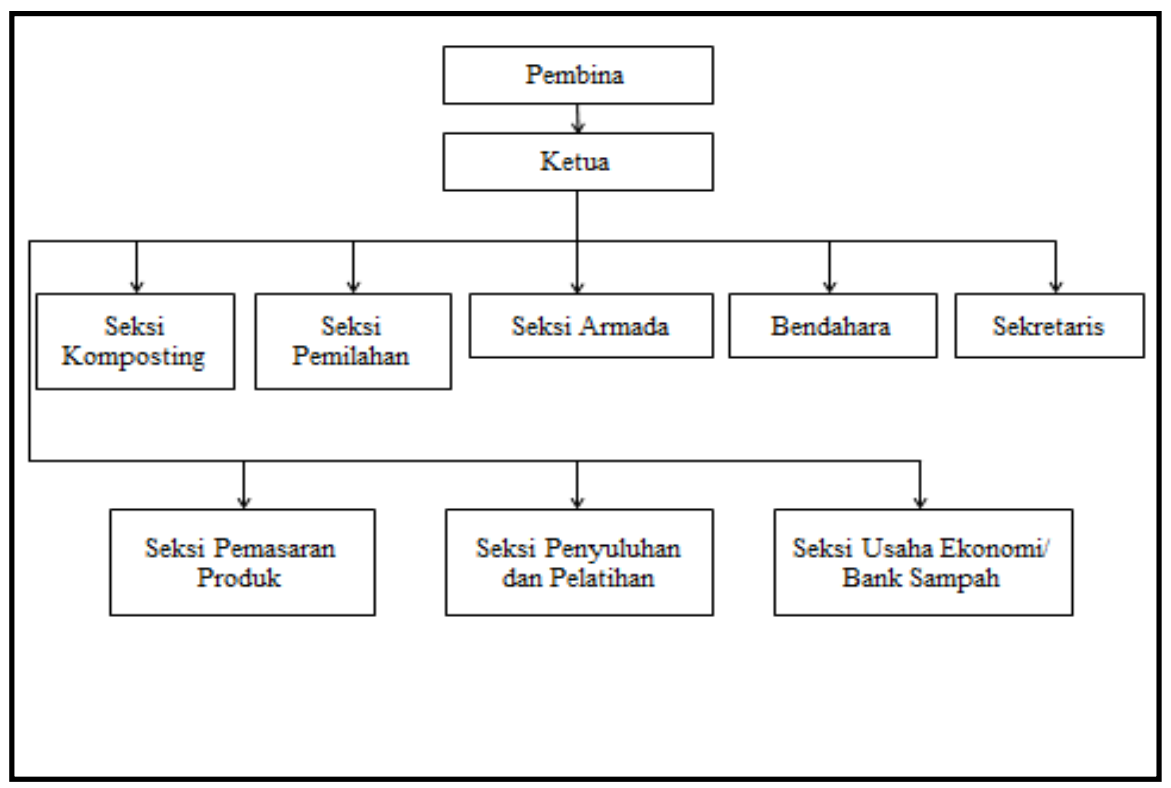

Gambar 4. Struktur kelembagaan di Bank Sampah Gampong Serambi Indah 
Yeggi Darnas et al., Pengelolaan Sampah Dengan Metode 3r Berbasis Gampong (Pilot Project: Gampong Serambi Indah, Kecamatan Langsa Barat, Kota Langsa)

2) Partisipasi masyarakat dalam pengelolaan sampah di Gampong Serambi Indah

Partisipasi yang dapat dilakukan masyarakat dalam pengelolaan sampah menurut Qanun nomor 3 Tahun 2014 pada Pasal 49 adalah sebagai berikut:

- Sosialisasi

- Masyarakat diberikan sosialisasi tentang pengelolaan sampah, dampak yang ditimbulkan jika sampah tidak ditangani dengan benar. Sosialisasi ini bertujuan agar masyarakat paham bahwa pentingnya menangani sampah dimulai dari sumber.

- Pewadahan

- Sesuai dengan tata cara partisipasi masyarakat dalam pengurangan dan penanganan sampah yaitu pada tahap pewadahan. Pewadahan yang dilakukan oleh masyarakat yaitu dengan menyediakan wadah yang sesuai dengan timbulan sampah yang dihasilkan. Pewadahan dipisah berdasarkan komposisi organik dan anorganik. Wadah yang digunakan berupa dua kantong plastik/tong sampah yang berukuran 10-40 L tiap rumah untuk menampung sampah sebanyak $5 \mathrm{~L} /$ hari.

- Tahap pengurangan barang (reduce), penggunaan ulang barang (reuse) dan daur ulang (recycle) (3R)

- Partisipasi masyrakat di Gampong Serambi Indah ini adalah dengan melakukan kegiatan 3R di rumah masingmasing, sehingga sampah yang diangkut ke TPA dapat berkurang.

- Partisipasi masyarakat dalam hal pembiayaan yaitu, masyarakat wajib membayar iuran yang telah ditetapkan setiap bulannya.

- Partisipasi masyarakat dalam hal mengolah sampah yaitu, masyarakat telah memilah sampah organik dengan anorganik agar sampah organik bisa diolah menjadi pupuk kompos.

- Partisipasi masyarakat sebagai pengelola sampah yaitu, masyarakat ikut berpartisipasi dengan melakukan kegiatan gotong royong.

- Partisipasi masyarakat sebagai pengawas yaitu, masyarakat menjaga sistematika pengelolaan sampah agar tetap berjalan dan berlaku di gampong.

\section{SIMPULAN}

Kesimpulan yang dapat diambil pada penelitian ini adalah:

1. Timbulan sampah yang dihasilkan pada Gampong Serambi Indah yaitu sebanyak $0,14 \mathrm{~kg} / \mathrm{orang} / \mathrm{hari}$ atau 1,16 L/orang/hari.

2. Partisipasi masyarakat Gampong Serambi Indah yang didapatkan berdasarkan wawancara sebesar $82 \%$ masih buruk (masyarakat belum ikut berpartisipasi dalam pengelolaan sampah). Dan 97\% masyarakat menyatakan butuhkan partisipasi masyarakat agar pengelolaan sampah berbasis gampong dapat berjalan dengan baik.

3. Perencanaan pengelolaan sampah di Gampong Serambi Indah yaitu pengadaan TPS 3R yang pengelolaannya dijalankan menjadi Bank Sampah dengan melibatkan masyarakat agar ikut berpartisipasi baik secara aktif maupun pasif. Untuk itu dilakukan sosialisasi terlebih dahulu. Jika masyarakat telah berpartisipasi dalam hal pemilahan dan pengomposan maka sampah yang diangkut ke TPA dapat berkurang 59\% yaitu sebesar $181 \mathrm{~kg}$ dari $370 \mathrm{~kg}$.

\section{Saran}

Adapun saran yang dapat disampaikan yaitu:

1. Untuk menciptakan lingkungan yang bersih dan sehat diperlukan kerjasama antar masyarakat, agar mandiri dalam mengelola sampahnya sendiri.

2. Adanya penyuluhan dan sosialisasi tentang pengelolaan sampah secara rutin yang diadakan pihak perguruan tinggi/pihak ketiga/gampong/pemerintah daerah kepada masyarakat agar masyarakat kontiniu mengelolaa sampahnya.

3. Setiap instansi dari tingkat gampong hingga ke pemerintahan pusat, hendaknya menyediakan dana khusus untuk pengelolaan sampah.

\section{DAFTAR PUSTAKA}

Agunggunanto, E. Y., Arianti, F., Kushartono, E. W., \& Darwanto. (2016). Pengembangan Desa Mandiri Melalui Pengelolaan Badan Usaha Milik Desa (BUMDes). Jurnal Dinamika Ekonomi Dan Bisnis, 13(No 1), 67-81.

Retrieved from http://e-journal.upp.ac.id/index.php/fekon/article/view/378/384

Astuti, Y. C. (2013). Hubungan Antara Dukungan Sosial Dengan Coping Strategy Pada Ibu Yang Memiliki Anak

Penyandang Tunagrahita: Studi Deskriptif Korelasional pada Ibu yang Memiliki Anak Tunagrahita Di SLB-C

YPLB Cipaganti Kota Bandung (Doctoral dissertation, Universitas Pendidikan Indonesia).

Badan Pusat Statistik Kota Langsa Tahun (2019).

Badan Standardisasi Nasional, R. (1995). Standar Nasional Indonesia SNI 19-3983-1995: Spesifikasi Timbulan 
Yeggi Darnas et al., Pengelolaan Sampah Dengan Metode 3r Berbasis Gampong (Pilot Project: Gampong Serambi Indah, Kecamatan Langsa Barat, Kota Langsa)

Sampah untuk Kota Kecil dan Kota Sedang di Indonesia, 31.

Damanhuri, Enri dan Tri Padmi. (2016). Pengelolaan Sampah Terpadu. Bandung: ITB.

Damanhuri, Enri dan Tri Padmi. (2010). Permasalahan Sampah.Bandung: ITB.

Darnas, Y. (2016). Studi Kelayakan Lokasi Tempat Pemrosesan Akhir ( Tpa ) Sampah Kabupaten Padang Pariaman.

Darnas, .Y, Anas, .A .A and Hasibuan, .M .A .A. (2020). Pengendalian Air Lindi Pada Proses Penutupan TPA Gampong Jawa Terhadap Kualitas Air Sumur. Jurnal Serambi Engineering,Volume 5, No.3, Fakultas Teknik Universitas Serambi Mekkah.

Dewilda, Y., Darnas, Y., \& Zulfa, I. (2014). Kabupaten Tanah Datar. Jurnal Teknik Lingkungan UNAND, 11(1), 2833.

Donna, Asteria dan Heru Heruman. (2016). Bank Sampah Sebagai Alternatif Strategi Pengelolaan Sampah Berbasis Masyarakat di Tasikmalaya. Volum 23 Nomor 1. Depok: FISIP UI.

Hartati, H., Indrawati, I., Sitepu, R., dan Tamba, N. (2019, May). Metode Aritmatika, Metode Aritmatika Dan Metode Eksponensial Untuk Memproyeksikan Penduduk Provinsi Sumatera Selatan. In Prosiding Seminar Nasional Sains, MIPA, Informatika dan Aplikasi (ISBN: 978-602-98559-1-3) (Vol. 4, No. 4).

Imamuddin, I. (2018). Partisipasi masyarakat dalam pengelolaan Badan Usaha Milik Desa (BUMDESa): studi kasus di Desa Payaman Kecamatan Solokuro Kabupaten Lamongan. Retrieved from http://digilib.uinsby.ac.id/id/eprint/27549

Iskandar, A. (2006). Daur Ulang Sampah. Jakarta: Azka Mulia Media.

Kementerian Perencanaan Pembangunan Nasional/ Badan Perencanaan Pembangunan Nasional. (2014). Rencana Pembangunan Jangka Menengah Nasional 2015-2019, 313. https://doi.org/10.1017/CBO9781107415324.004

Lingkungan, M., Dan, H., \& Republik, K. (2018).

Mallongi, A. Dan Saleh, M., (2015). Pengelolaan sampah PadatPerkotaan. Makassar: WR.

Maryuliana, M., Subroto, I. M. I., dan Haviana, S. F. C. (2016). Sistem informasi angket pengukuran skala kebutuhan materi pembelajaran tambahan sebagai pendukung pengambilan keputusan di sekolah menengah atas menggunakan skala likert. TRANSISTOR Elektro dan Informatika, 1(1), 1-12.

Nugraha, A, Surjono H.S dan Akhmad, A.A. (2018).Volum 8. Nomor 1. Persepsi dan Partisipasi Masyarakat Terhadap Pengelolaan Sampah Rumah Tangga Melalui Banks Sampah di Jakarta Selatan. Jurnal Pengelolaan Sumberdaya Alam dan Lingkungan. Bandung: IPB.

Nur, Sulistiyorini, Rahmawati. Rudi Saprudin Darwis dan Arie Surya Gutama. (2016). Partisipasi Masyarakat dalam Pengelolaan Sampah Lingkungan Margaluyu Kelurahan Cicurug. Volume 5. Nomor 1. Halaman 1. Majalengka.

Perpres No 97 Tahun 2017 tentang Jakstranas Pengelolaan Sampah Rumah Tangga.pdf. (n.d.).

Pedoman Sampah RT.pdf. (n.d.).

Qanun Kota Langsa Nomor 3 Tahun 2014. Tentang Pengelolaan Sampah.

Rahbil, Fadly, Andi. (2017). Studi Pengelolaan Bank Sampah Sebagai Salah Satu Pendekatan dalam Pengelolaan Sampah yang Berbasis Masyarakat (Studi Kasus Bank Sampah Kecamatan Manggala). Gowa: Prodi Teknik Lingkungan Universitas Hasanuddin.

Rohani, Lasma. (2007). Perilaku Masyarakat dalam Pengelolaan Sampah di Desa Medan Senembah Kabupaten Deliserdang dan di Kelurahan Asam Kumbang Kota Medan 2007.

Shihab, Q. (2009). Tafsìr Al-Mishbah (Pesan, Kesan dan Keserasian al-Qur'ān). Volume 11. Jakarta: Lentera Hati.

SNI 19-2452-2002. Pengelolaan Sampah Perkotaan.

SNI 19-3964-1994. Metode Pengambilan dan Pengukuran Contoh Timbulan dan Komposisi Sampah Perkotaan.

Soekidjo, N. (2011). Kesehatan Masyarakat: Ilmu dan Seni. Jakarta: PT. Rineka Cipta.

Subekti, Sri. (2010). Pengelolaan Sampah Rumah Tangga 3R Berbasis Masyarakat. Fakultas Teknik: Universitas Wahid Hasyim Semarang.

UU No.18. (2008). UU No 18 Tentang Pengelolaan Sampah. Republik Indonesia, 1-46.

Yuliastuti, I.A.N, Yasa, I.M. (2013). Partisipasi Masyarakat dalam Pengelolaan Sampah di Kabupaten Bandung. Jurnal Ekonomi dan Bisnis. Bandung: Universitas Udayana. 